\title{
Use of a High-Power Laser for Wound Healing: A Case Report
}

\author{
Fábio Luiz Costa Pereira ${ }^{1 *}$, Marcus Vinicius Lucas Ferreira ${ }^{2}$, Pablo da Silva Mendes ${ }^{1}$, Fabrício Machado Rossi ${ }^{1}$, \\ Mariana Pereira Alves ${ }^{3}$, Bernadete Luzia Pereira Alves $^{3}$
}

${ }^{1}$ Capixaba Institute of Angiology, Vitória, ES, Brazil

${ }^{2}$ Faculty of Dentistry, Universidade Federal de Minas Gerais, Belo Horizonte, MG, Brazil

${ }^{3}$ Dental Surgeon, Private Practice, Vitória, ES, Brazil

*Correspondence to

Fábio Luiz Costa Pereira, Rua

Professor Sarmento, 125/806,

Enseada do Suá, Vitória, ES,

Brazil, Cep: 29052-370.

Tel: 55-27-999330201;

Email:mvlcas@uol.com.br

Published online January 18 , 2020

\begin{abstract}
Introduction: The use of low-level laser therapy to treat wounds and accelerate tissue healing has extensively been studied in recent years. The aim of this article is to describe a clinical case using an unfocused high-power laser instead of a low-power laser for therapy.

Case Report: In the present article, we present the use of a high-power diode laser to treat an extensive knee injury that occurred after surgical treatment for total prosthesis due to border ischemia resulting from prolonged use of autostatic retractors.

Conclusion: It is possible to use an unfocused high-power laser at a decreased intensity to accelerate healing as an adjuvant in the treatment of complicated wounds. This procedure results in reduced application time and cost and an excellent tissue response pattern similar to that reported in the literature with low-power lasers.

Keywords: Transdermal laser; Wound healing; High-power laser.
\end{abstract}

\section{Introduction}

Low-power lasers and LEDs have been used in phototherapy in recent years to accelerate wound healing in patients with a local or systemic issue in which the healing process is altered. ${ }^{1-4}$

Several studies have shown that photobiomodulation with lasers or LEDs effectively treats wounds and accelerates healing both in experimental models and in humans. ${ }^{2-5}$ However, the vast majority of studies have used low-power lasers and LEDs.

The aim of this case report is to show that an unfocused high-power laser offers similar benefits to a low-power laser but with shorter exposure time and fewer sessions. An unfocused high-power diode laser $(10 \mathrm{~W})$ was used to treat poorly healing wounds. The application time and the number of treatment sessions were reduced compared to those reported in studies using low-intensity lasers.

\section{Case Report}

The patient AGP (76 years, female) presented with an iatrogenic ischemic ulcer caused by prolonged use of a retractor during orthopedic surgery for total knee prosthesis without changes in her blood macrocirculation. The lesion was considered difficult to treat with traditional methods because it demonstrated a high potential risk to the functional viability of the affected limb after 28 days of hyperbaric oxygen therapy (23 daily, uninterrupted sessions) without improvement.

The patient underwent one transdermal high-intensity laser therapy session each week for a total of twelve sessions. A diode laser with a wavelength of $980 \mathrm{~nm}$ and a power of $10 \mathrm{~W}$ was used with continuous emission. The beam-irradiated area was $10 \mathrm{~mm}$ in diameter, and the focal length was $6 \mathrm{~cm}$ between the fiber and the irradiated area, which was standardized using the handpiece of the device. The applications were performed using the scanning technique with a velocity of $1 \mathrm{~cm} / \mathrm{s}$. The approximate energy density was $3.18 \mathrm{~J} / \mathrm{cm}^{2}$.

The total time averaged 78 seconds for each application in the initial phase and was gradually reduced as the lesion started to heal. One application in each weekly session was considered sufficient to deliver the energy density necessary to achieve the desired result. The treated wound had an area of approximately $245 \mathrm{~cm}^{2}$. The laser application was simple and painless and did not require any anesthesia or associated analgesia. During the intervals between laser application sessions, the patient was advised to maintain proper hygiene of the lesion. The need for analgesics for pain control on the days between sessions was greatly reduced after treatment started. As the lesion began to heal, the irradiation time was reduced according to the extent of lesion reduction. The high- 
power laser sessions followed the scanning technique with a velocity of $1 \mathrm{~cm} / \mathrm{s}$ and approximate energy density of $3.18 \mathrm{~J} / \mathrm{cm}^{2}$.

The treatment sessions started after surgical resection of the necrotic tissue, which was visible as a black crust covering the wound (Figure 1A), with the patient under sedation. An area covered with seropurulent secretion and an abundance of fibrin was present below the crust (Figure 1B). Laser application was performed according to the described methodology. After starting the transdermal high-power laser application, a reduction in exudates and perilesional edema was observed along with a consequent reduction in the area covered by crust and devitalized tissue.

During the first week, a significant reduction in secretion was observed, and the area covered by fibrin was replaced by granulation tissue. This condition developed progressively in each session (Figures 2A; 2B; $3 \mathrm{~A})$. Similarly, concentric and rapid epithelialization of all wound borders occurred (Figures 3B and 4). Complete wound healing occurred 64 days after treatment began. It was also noted that the scar tissue pattern had a flat and organized structure with characteristics similar to the adjacent normal skin with no retraction or keloid formation.

\section{Discussion}

According to the nature and extent of the wound and damaged tissue, cutaneous lesions may heal by primary or secondary intention. In extensive cutaneous lesions, tissue loss results in difficult or even impossible border approximation; therefore, secondary intention healing is the natural method of tissue restoration. This is a slower process with a high risk of infection. This type of healing produces contraction of the scar and extensive scarring and often involves high treatment costs. Laser therapy is associated with reduced inflammatory infiltration intensity. The radiation emitted by lasers in the red and infrared range promotes increased fibroblast proliferation and accelerates wound epithelialization. ${ }^{6}$ Hawkins et $\mathrm{al}^{6}$ evaluated changes in the wound area of humans treated

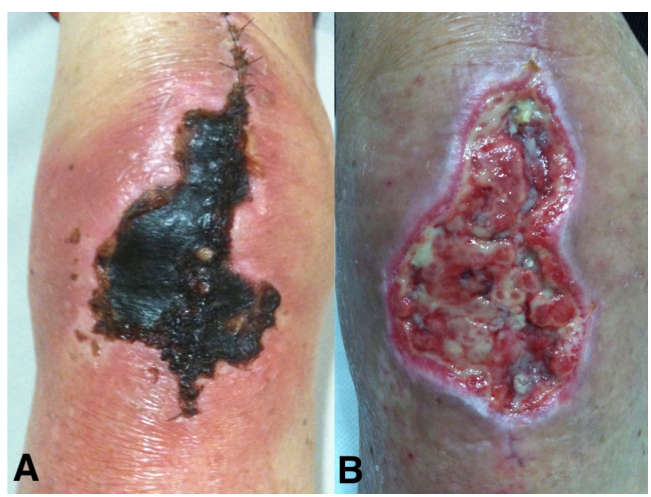

Figure 1. (A) Lesion Covered by Necrotic Crust. (B) Lesion After the Removal of Necrotic Crust. with an $820 \mathrm{~nm}$ diode laser at $8 \mathrm{~J} / \mathrm{cm}^{2}$. They found that by the sixth day, wounds that had been irradiated with the laser had a $153 \%$ greater area reduction than wounds in a control group. According to Mejía et al, ${ }^{7}$ it is possible to reduce the healing time of wounds by $40 \%$ with a lowintensity laser.

According to reports in the scientific literature, the application of low-level laser therapy in the treatment of wounds accelerates wound healing time by influencing both inflammatory and proliferative phases and also stimulates a more harmonious and organized healing process, ultimately producing better aesthetic results in the scar tissue. , $, 4,6,8-10^{-}$

Recently, high-power lasers have been used in an unfocused manner or at a lower intensity than those used in cutting or coagulation to achieve the same biomodulatory effects of low-power lasers. Peat et $\mathrm{al}^{11}$ conducted a study on the effects of in vitro photobiomodulation with highpower lasers on the viability and cytokine expression of bone marrow-derived mesenchymal stem cells. They concluded that high-power laser photobiomodulation of these mesenchymal stem cells produces an antiinflammatory effect and thus improves the therapeutic properties of these cells for musculoskeletal disease

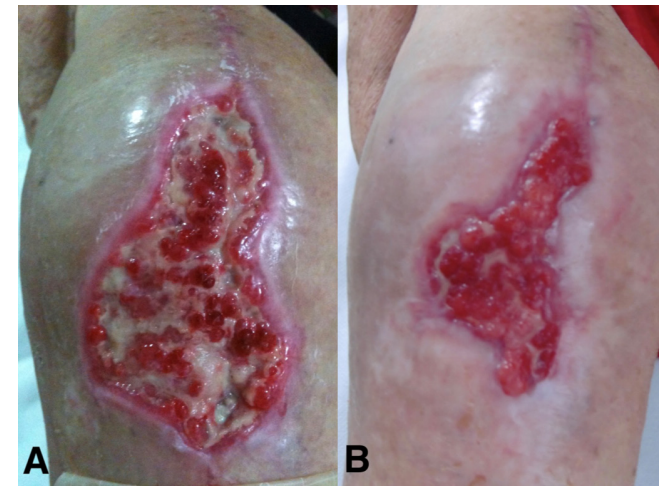

Figure 2. (A) Initial Granulation. (B) Granulation Occupies Almost the Entire Lesion.

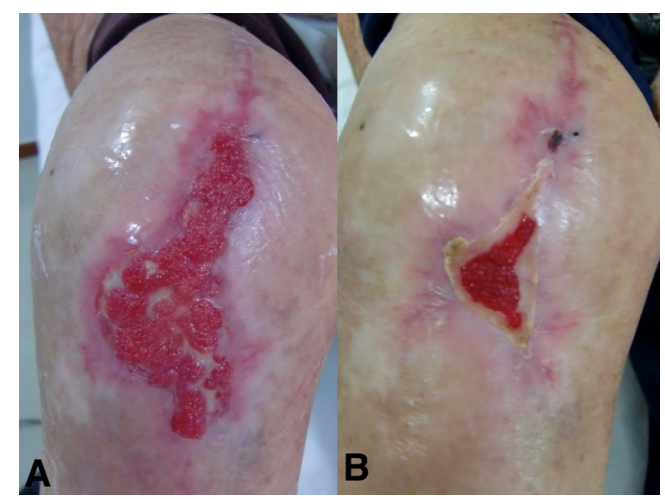

Figure 3. (A) Fine and Regular Granulation. (B) Considerably Reduced Lesion. 


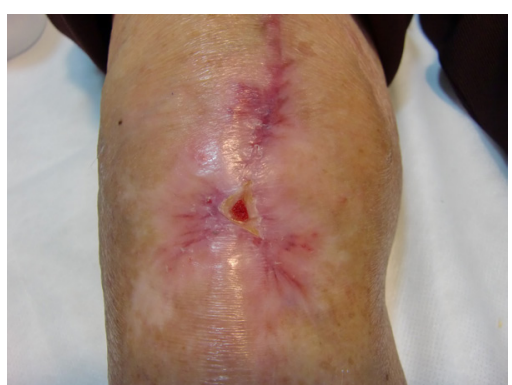

Figure 4. (A) Nearly Complete Healing With No Hyperplasia.

treatment without affecting cellular survival and by positively regulating IL-10 and VEGF expression. IL10 is anti-inflammatory and inhibits proinflammatory cytokine synthesis, and VEGF is a positive regulator of angiogenesis during tissue healing. Angelova and IIieva ${ }^{12}$ conducted a pilot study to evaluate the effectiveness of high-power lasers in reducing pain after knee osteoarthritis; they found that laser treatment resulted in reduced pain and improved knee function and offered a better quality of life for these patients.

The use of high-power lasers to perform photobiomodulation as described in this study significantly decreases the duration of laser therapy sessions; thus, more patients can be treated in a limited period of time. The disadvantages of these devices include their cost, which is higher than that of low-intensity lasers, and the need for greater expertise to prevent undesirable effects such as burns and pain.

\section{Conclusion}

Treatment with an unfocused high-power laser at a dose of $3.18 \mathrm{~J} / \mathrm{cm}^{2}$ applied once a week was effective in aiding the healing process and tissue repair of the treated patient. The use of unfocused high-power lasers to treat poorly healing wounds offers advantages, such as decreased application time, painless sessions, reduced analgesic use, and no healing problems such as retraction or keloid formation, as observed in this specific case. Larger studies are needed to determine the effects and safety parameters when using unfocused high-power lasers for wound healing.

\section{Ethical Considerations}

The patient gave written informed consent prior to receiving treatment.

\section{Conflict of Interests}

The authors declare that they have no conflicts of interest to disclose.

\section{References}

1. Da Silva JP, Da Silva MA, Almeida AP, Lombardi JI, Matos AP. Laser therapy in the tissue repair process: A literature review. Photomed Laser Surg. 2010;28(1):17-21. doi:10.1089/PHO.2008.2372

2. Franek A, Krol P, Kucharzewski M. Does low output laser stimulation enhance the heal-ing of crural ulceration? Some critical remarks. Med Eng Phys. 2002;24(9):607-15. doi:10.1016/S1350-4533(02)00112-1

3. Al-Watban FA, Andres BL. Polychromatic LED therapy in burn healing of non-diabetic and diabetic rats. J Clin Laser Med Surg. 2003;21(5):249-58. doi:10.1089/104454703322564451

4. Demir H, Menku P, Kirnap M, Calis M, Ikizceli I. Comparison of the effects of laser, ul-trasound, and combined laser + ultrasound treatments in experimental tendon healing. Lasers Surg Med. 2004;35(1):84-9. doi. org/10.1002/lsm.20046

5. Ng GY, Fung DT, Leung MC, Guo X. Comparison of single and multiple applications of GaAlAs laser on rat medial collateral ligament repair. Lasers Surg Med. 2004;34(3):2859. doi:10.1002/lsm.20015

6. Hawkins D, Abrahamse H. Effect of multiple exposures of low-level laser therapy on the cellular responses of wounded human skin fibroblasts. Photomed Laser Surg. 2006;24(6):705-14. doi:10.1089/pho.2006.24.705

7. Mejía PAL, Butrón HL, Hernández AMM, Ruíz AR, López ESG. Reduction of healing time by means of helium-neon laser, Experimental model in rabbits. Revista Mexicana de Ortopedia y Traumatología. 1999;13(5):455-8. [Spanish].

8. Schlager A, Kronberger P, Petschke F, Ulmer H. Lowpower laser light in the healing of burns: A comparison between two different wavelengths (635 $\mathrm{nm}$ and $690 \mathrm{~nm}$ ) and a placebo group. Lasers Surg Med. 2000;27(1):3942. doi:10.1002/1096-9101(2000)27:1<39:AIDLSM $5>3.0 . \mathrm{CO} ; 2-4$

9. Schlager A, Oehler K, Huebner KU, Schmuth M, Spoetl L. Healing of burns after treat-ment with 670-nanometer lowpower laser light. Plast Reconstr Surg. 2000;105(5):1635-9. doi: 10.1097/00006534-200004050-00006

10. Mester E, Mester AF, Mester A. The biomedical effects of laser application. Lasers Surg Med. 1985;5(1):31-9. doi:10.1002/1sm.1900050105

11. Peat FJ, Colbath AC, Bentsen LM, Goodrich LR, King MR. In vitro effects of high-intensity laser photobiomodulation on equine bone marrow-derived mesenchymal stem cell viability and cytokine expression. Photomed Laser Surg. 2018;36(2):83-91. doi.org/10.1089/pho.2017.4344

12. Angelova A, Ilieva EM. Effectiveness of high intensity laser therapy for reduction of pain in knee osteoarthritis. Pain Res Manag. 2016;9163618. doi:10.1155/2016/916361 